\title{
Avaliação das equipes de vendas de duas empresas com a matriz BCG utilizando lucro e margem de contribuição
}

\section{Evaluation of two companies' sales teams with the BCG matrix using profit and contribution margin}

ISSN 0104-530X (Print) ISSN 1806-9649 (Online)

\author{
Roque Alberto Zin ${ }^{1}$ \\ Ligia Pichetti Bombana ${ }^{2}$ \\ Paulo Fernando Pinto Barcellos ${ }^{3}$
}

\begin{abstract}
Resumo: No presente trabalho o método da matriz BCG foi adaptado para ser utilizado na avaliação do desempenho das equipes de vendas de duas empresas de segmentos e tamanhos diferentes, sendo uma empresa fabricante de móveis e a outra uma fabricante de fios especiais para tricô e decoração. Depois de apurados os resultados, as equipes de vendas de ambas as empresas foram classificadas em uma matriz que relaciona o seu faturamento com a margem de contribuição e o lucro de cada uma. A classificação das equipes foi feita em relação aos resultados das empresas. A sua alocação em quadrantes ilustra o desempenho quantitativo e qualitativo de cada equipe de vendas em relação à média da empresa. Os resultados mostram a similaridade de posicionamento das equipes de venda, mesmo tratando-se de empresas em segmentos diferentes, bem como as distorções geradas com o uso de rateio de custos fixos na análise de desempenho.
\end{abstract}

Palavras-chave: Avaliação de desempenho; Matriz BCG; Equipe de vendas; Margem de contribuição.

\begin{abstract}
In this study, the BCG matrix method was adapted to evaluate the sales teams' performance of two companies of different sizes and from different segments: a furniture manufacturer and a manufacturer of special yarns for knitting and decoration. Results show that both companies'sales teams were classified into a matrix that relates their revenues to their respective contribution margins and profits. The sales teams' classification was made in relation to company results. Its quadrant allocation illustrates the quantitative and qualitative performance of each sales team in relation to the company average. The results show the similarity of sales teams' positioning, even when dealing with companies from different segments, as well as the distortions generated through the use of fixed cost apportionment in performance analysis.
\end{abstract}

Keywords: Performance evaluation; BCG matrix; Sales team; Contribution margin.

\section{Introdução}

O presente trabalho teve por objetivo interligar ferramentas de gestão estratégica com dados financeiros de forma a avaliar o desempenho da força de vendas de uma organização. Conforme Damodaran (2007), em todas as organizações há um momento em que os projetos, planejamentos e outras formas de gestão se transformam em números. Os controles buscam não somente avaliar o desempenho passado como, também, podem interferir nas decisões e no comportamento futuro. Para Wilkes et al. (2005), as organizações devem utilizar os controles para influenciar o comportamento das pessoas como membros da organização, tornando-se necessários para motivar as pessoas na direção dos objetivos organizacionais.

De acordo com Merchant (1998), estabelecer um controle gerencial é buscar respostas para a seguinte questão: nossos empregados estão tendo um comportamento adequado? A resposta envolve uma série de ações que permitam fazer com que os funcionários saibam o que se espera deles e protejam os interesses da organização, envolvendo

\footnotetext{
${ }^{1}$ Universidade de Caxias do Sul - UCS, Rua Julio de Castilhos, 3308, CEP 95270-000, Flores da Cunha, RS, Brasil, e-mail: roque@majorem.com.br

${ }^{2}$ Universidade de Caxias do Sul - UCS, Rua Waldemar M. Grazziotin, 710, CEP 95250-000, Antônio Prado, RS, Brasil, e-mail: lipechetti@hotmail.com

${ }^{3}$ Universidade de Caxias do Sul - UCS, Rua Jornal do Brasil, 111, apto. 1.111, CEP 95050-050, Porto Alegre, RS, Brasil, e-mail: pfbarce@ucs.br
} 
sua cultura. Para Owoyemi \& Ekwoaba (2014), uma cultura organizacional forte é uma ferramenta para a gerência controlar, motivar e melhorar o desempenho dos empregados, como por eles investigado em uma organização governamental de Lagos, na Nigéria. De outra parte, Ladley et al. (2015) examinaram o efeito da avaliação individual e sistemas de recompensas versus o de grupos no comportamento e desempenho no trabalho, descobrindo que os sistemas baseados em grupos superam aqueles baseados no indivíduo, produzindo mais comportamento cooperativo.

Uma das características do bom controle é a de dirigir os objetivos que a organização espera atingir. Dessa forma, ele se transforma em ferramenta valiosa de informação confiável. Uma das formas de evitar problemas de controle, na visão de Merchant (1998), é compartilhar os riscos, aspecto que pode limitar as perdas que poderiam surgir de um comportamento inadequado, bem como tornar mais justas as compensações monetárias que envolvem esforço pessoal, como é a atividade de venda.

No presente trabalho, o método da matriz BCG criado pelo Boston Consulting Group para a avaliação do portfólio de produtos foi aplicado na avaliação do desempenho das equipes de venda de duas empresas diferentes. O objetivo foi avaliar o desempenho das equipes de venda em relação aos resultados totais da respectiva empresa, por esse motivo não foi feita a comparação com o potencial de mercado. Será que as equipes de venda das empresas podem ser classificadas como um portfólio de equipes e colocadas numa matriz BCG conforme o seu desempenho relativo? Para responder a essa questão foram estudadas duas empresas de segmentos de mercado diferentes e de tamanho diferente.

O trabalho iniciou-se com a apuração dos custos totais de cada unidade produzida. Após a apuração dos custos variáveis, os gastos fixos foram rateados e alocados em cada produto, de forma a calcular a margem de contribuição e o lucro de cada unidade vendida.

Após apurados os resultados por produto, foi feito o levantamento das vendas de cada equipe e deduzidos os custos correspondentes. Com isso foi possível avaliar a participação de cada equipe nos resultados da empresa respectiva. Os resultados mostram que o posicionamento das equipes de venda em relação ao desempenho das empresas são semelhantes nas duas organizações, mostrando o posicionamento estratégico das equipes em relação aos resultados das firmas. Esses resultados podem servir para a avaliação qualitativa de cada equipe e para a elaboração de estratégias com relação ao desempenho comercial das empresas.

$\mathrm{O}$ artigo está estruturado como segue: após a introdução apresentam-se considerações teóricas sobre a necessidade e utilidade de controles, nas quais se comenta a utilização da matriz BCG como ferramenta; em seguida são abordados os diferentes usos da matriz além do portfólio de produtos; então é descrito o levantamento de dados bem como são analisados os resultados conforme as margens de contribuição e margens de lucro. Ao final são feitas algumas recomendações sobre o uso da matriz BCG e sugestões para estudos futuros.

\section{Controles}

A medição do desempenho de negócios visando seu controle tem sido objeto de estudo tanto de gestores quanto de pesquisadores em contabilidade gerencial (Otley, 1999). Para a gestão de equipes de venda, a importância do controle é destacada em estudo realizado no México por Rajagopal \& Rajagopal (2008).

O controle, na visão de Flamholtz (1996), é uma forma de integrar o esforço das pessoas e fazer com que tenham a mesma direção, uma vez que os indivíduos têm interesses diferentes, bem como tarefas e perspectivas diversas. Para ele, o controle tem quatro funções: a primeira é motivar as pessoas de forma a que as suas decisões e ações sejam consistentes com os objetivos organizacionais. Sem um sistema de controle, as pessoas podem decidir de acordo com as suas necessidades ao invés das metas organizacionais. Outra função é integrar os esforços das diferentes partes da organização, mesmo quando as pessoas têm suas ações direcionadas aos interesses organizacionais. Sem controle efetivo, elas podem estar trabalhando de forma diversa e desperdiçando recursos. A terceira função de um sistema de controle é fornecer informações sobre os resultados operacionais e o desempenho das pessoas. Ao mesmo tempo em que essas informações se disseminam pela organização e avaliam os resultados, permitem ajustes em curto prazo, sem a necessidade de revisão de todas as decisões. A quarta função é a implementação de planos estratégicos.

Em sua proposição, Flamholtz (1996) coloca cinco passos para um sistema de controle ser efetivo: (1) planejamento; (2) atividades operacionais; (3) estabelecimento de medidas; (4) geração de feedback; (5) sistema de avaliação e recompensa. É conveniente destacar que a recompensa deve resultar de um processo em que o critério de avaliação utilizado estabeleça claramente justiça entre os avaliados, pois foi evidenciada, em estudo realizado por Lopes et al. (2011), a influência da justiça percebida na ligação psicológica da equipe de vendas com a empresa.

Na maioria das empresas em que a força de vendas é terceirizada, a remuneração é estabelecida através de um percentual de comissão sobre o preço de venda, independentemente do volume ou da lucratividade obtida com a venda. Essa característica revela uma questão cultural das empresas, na qual o aspecto preponderante é a venda, ou seja, pouca atenção é dada a aspectos orçamentários e de resultados. Isso é ressaltado pela forma como são estabelecidos 
os objetivos comerciais, geralmente expressos em volumes de unidades vendidas ou valor a ser atingido.

Uma das razões para essa ocorrência é a simplicidade e a facilidade. Esse aspecto está em linha com o que coloca Ouchi (1979) em sua afirmação de que dentro do desenho do controle organizacional há dois aspectos relevantes que determinarão qual forma de controle será mais eficiente. O primeiro é a clareza com que o desempenho pode ser avaliado e o segundo é o grau de incongruência das metas.

\section{Matriz BCG e controle}

De acordo com Kotler \& Keller (2016), uma das formas de avaliar o portfólio de produtos é a matriz BCG de crescimento-participação, que se tornou popular sob a sigla da empresa que a criou, conhecida como matriz BCG. Considerada de grande utilidade na análise de portfólio de produtos e posicionamento da empresa no ambiente externo, ela avalia o portfólio através do fluxo de caixa gerado. Para tanto, coloca no eixo vertical a taxa de crescimento do mercado e no eixo horizontal a participação relativa da empresa. Com esses dois indicadores são gerados quatro quadrantes que demonstram a posição dos produtos da empresa com as seguintes características:

Ponto de interrogação: refere-se a produtos ou negócios que operam em mercados de alto desenvolvimento, porém com baixas participações relativas. É uma fase que requer investimentos para acompanhar o crescimento da participação de mercado.

Estrela: ocorre quando os produtos ou negócios considerados pontos de interrogação tornam-se bem-sucedidos. Esses têm grande participação relativa em mercado de alto crescimento, sem necessariamente apresentar fluxo de caixa positivo.

Vaca leiteira: de acordo com Kotler \& Keller (2016), ocorre quando a taxa de crescimento de mercado começa a cair de forma significativa, porém, o produto ou o negócio apresenta elevada participação relativa no mercado. Dessa forma, Estrelas tornam-se Vacas leiteiras. Nesse quadrante da matriz são gerados fluxos de caixa positivos e grandes margens de lucro.

Abacaxi: são aqueles produtos ou negócios com baixa participação relativa em mercados de pouco crescimento. Geralmente geram prejuízos, mas, por algum motivo, continuam fazendo parte do portfólio da empresa.

\section{Usos da matriz}

A matriz BCG já foi empregada com outras finalidades além da de analisar o portfólio de produtos. Connel (2010) a utilizou para ajudar a desenvolver políticas públicas de desenvolvimento econômico, nas quais o eixo vertical representou a competitividade de setores econômicos e o eixo horizontal, sua atratividade. Após análise, os mesmos foram classificados nos quadrantes da matriz de acordo com sua prioridade.
Conforme Calandro \& Lane (2007), a matriz BCG é muito utilizada na indústria de seguros, na qual ajudam os executivos sêniores a identificar os segmentos de mercado de maior potencial e, com isso, a definir a alocação de recursos de forma a trazer o maior retorno possível.

Os críticos da matriz de crescimento-participação afirmam que uma das suas fragilidades é que se pode definir o tamanho do mercado e a participação de cada empresa de várias maneiras. Porém, para Walter Kiechell III, editor da Harward Business Publishing e autor do livro The Lords of Strategy: The Secret Intellectual History of the New Corporate World, a matriz tem muita utilidade, pois não deixa os gestores à mercê dos gerentes de unidades ou de produtos, já que "[...] a mensagem subjacente da matriz é que você tem dados para entender o próprio negócio, sua situação competitiva e o provável potencial, tão verdadeiros quanto possível" (Allio \& Randall, 2010, p. 30).

A questão desenvolvida neste trabalho é sobre a possibilidade de utilizar a matriz BCG para avaliar qualitativamente uma equipe de vendas, considerando o desempenho relativo de seus componentes em relação aos resultados da empresa. Geralmente, a avaliação envolve a quantidade vendida e o cumprimento de metas, mas este trabalho pretendeu avaliar o desempenho das equipes em relação a margem de contribuição e margem de lucros gerados.

A análise foi feita em relação ao desempenho interno. Para tanto foram estabelecidas as seguintes premissas:

A -Lucro da empresa: Com base no lucro apresentado pela empresa foi calculado o lucro médio de cada equipe comercial. Acima dessa média, a equipe foi considerada de "lucro alto", abaixo da média, a equipe foi enquadrada como "lucro baixo";

B -Margem de contribuição: Com base na margem de contribuição total foi calculada a média aritmética. Essa média foi considerada o ponto de corte das avaliações de desempenho. A equipe comercial com lucro acima dessa média sfoi considerada como de "contribuição alta". Abaixo dessa média foi considerada como de "contribuição baixa";

$\mathrm{C}-\mathrm{O}$ volume de vendas da empresa em moeda corrente foi dividido pelo número dos componentes da equipe de vendas. Aqueles que tiveram desempenho acima dessa média foram considerados como de "alto volume" de vendas e os que ficaram abaixo da média, como de "baixo volume" de vendas. Conforme informações das empresas analisadas, as áreas 
de atuação das equipes de venda foram definidas de acordo com a conveniência das equipes contratadas como prestadoras de serviço. Não foi considerado o desempenho das equipes em relação ao potencial de mercado, pois as empresas não possuem essas informações. $\mathrm{O}$ trabalho se propôs a posicionar as equipes de venda no escopo da empresa para avaliar estrategicamente o posicionamento e propor ações a serem implementadas.

Após a definição dos indicadores, a matriz de avaliação da equipe de vendas ficou com os critérios de classificação, equivalentes à matriz $\mathrm{BCG}$, conforme resumidos no Quadro 1.

\section{Coleta de dados}

Os dados foram coletados em duas empresas. Uma delas fabrica móveis e apresenta faturamento de 4,4 milhões de dólares anuais, o que a coloca como empresa de médio porte. Esse valor da receita em dólares foi obtido convertendo-se o valor em reais pelo dólar médio do ano analisado, código 3693 - taxa de câmbio - dólar americano - média de período anual, conforme informação do Banco Central. Essa taxa atende o pronunciamento técnico $\mathrm{CPC} 02$ do Comitê de Pronunciamentos Contábeis (CPC, 2010) que orienta a conversão das contas de resultado pela taxa cambial média do período. A sua linha de comercialização é composta de 156 produtos. A área de vendas é formada por 17 empresas vendedoras que atendem varejistas de todo o país e uma equipe interna que atende um único cliente, totalizando 18 equipes de vendas. As vendas são realizadas para o varejo que, por sua vez, atende o consumidor final. Não há vendas por meio virtual ou pacotes negociados diretamente pela empresa. Uma única rede de varejo é atendida por uma equipe interna, a qual recebe o mesmo tratamento das equipes externas, o que permitiu a análise comparativa.

A segunda empresa é uma indústria têxtil que produz fios especiais para a linha artesanal de tricô, tapeçaria e decoração. A sua linha de comercialização é composta por 11 produtos diferentes e o faturamento anual é equivalente a 460 mil dólares, o que a caracteriza como empresa de pequeno porte. A conversão do faturamento para o dólar foi feita com a média anual fornecida pelo Banco Central, código 3693 - taxa de câmbio - dólar americano - média de período anual, conforme recomendação do CPC 02. A área de vendas é composta por 10 empresas vendedoras que atendem o varejo de várias regiões do país.

Para cada produto foram calculados os custos variáveis de acordo com a sua composição. Respeitando-se os critérios adotados pela empresa, os gastos fixos foram rateados proporcionalmente aos custos variáveis.

Após o levantamento dos custos foram calculadas as margens de contribuição para cada produto comercializado. Para o cálculo do lucro de cada unidade vendida, o rateio dos custos fixos foi feito de três formas diferentes: pela mão de obra direta, pelo consumo de matéria-prima e pelos custos variáveis totais. Os resultados foram semelhantes em todos os critérios utilizados.

\subsection{Unidade de análise}

De acordo com Connel (2010), uma unidade de análise estratégica pode ser um produto ou uma linha de produtos para os quais as estratégias podem ser desenvolvidas. Neste caso, o objeto de análise será o desempenho da equipe de vendas em seu segmento (a área geográfica de atuação). A empresa de móveis possui 18 segmentos de vendas, sendo que 17 são atendidos por equipes terceirizadas e diretamente pela empresa. A empresa têxtil tem 10 segmentos que são atendidos por empresas terceirizadas que prestam serviços de representação comercial.

\section{Apuração do lucro}

Para apuração do lucro de cada unidade vendida foram calculados os custos variáveis, sendo os principais a matéria-prima e a mão de obra direta. Como despesas variáveis consideraram-se os tributos incidentes sobre as vendas, royalties e comissões pagas às equipes de vendas. Considerando-se o prazo médio de venda de cada equipe, os valores das vendas foram trazidos para o valor presente, para que não ocorresse distorção em relação aos prazos de pagamento utilizados.

Uma vez apuradas essas informações, a margem de contribuição de cada unidade vendida foi calculada da seguinte forma: do preço de venda praticado foram deduzidos os custos variáveis e as despesas variáveis. Das vendas totais de cada equipe foram deduzidos os custos variáveis totais e as despesas variáveis totais,

Quadro 1. Comparativo da matriz BCG para portfólio de produtos e da matriz para análise de vendas.

\begin{tabular}{|c|c|c|}
\hline & Estrela & Ponto de interrogação \\
\hline Matriz BCG & Alto crescimento $\times$ alta participação & Alto crescimento $\times$ baixa participação \\
\hline Matriz vendas & Alto volume $\times$ alto lucro & Alto volume $\times$ baixo lucro \\
\hline & Vaca leiteira & Abacaxi \\
\hline Matriz BCG & Baixo crescimento $\times$ alta participação & Baixo crescimento $\times$ baixa participação \\
\hline Matriz vendas & Baixo volume $\times$ alto lucro & Baixo volume $\times$ baixo lucro \\
\hline
\end{tabular}

Fonte: Autores. 
obtendo-se, assim, a margem de contribuição de cada equipe de vendas.

Após a apuração da margem de contribuição de cada produto foi calculado o lucro. Para isso, os demais gastos foram considerados fixos, sendo feito um rateio para se calcular o valor a ser absorvido pelas unidades vendidas. O lucro de cada unidade vendida foi multiplicado pelo número de unidades vendidas de cada equipe e, com isso, obteve-se o lucro de cada uma das equipes.

\subsection{Posicionamento da indústria de móveis}

Como o objetivo da aplicação é comparar a posição relativa de cada uma das equipes de venda, foi considerada a média de desempenho da empresa como linha de corte para definir o posicionamento. Como o faturamento total da empresa no ano analisado foi de aproximadamente 5 milhões de dólares (US\$ 4.937.957,60), atingido com 18 equipes de vendas, das quais 17 externas e uma interna, a média de vendas foi de US\$274.330,97 por equipe. Os dados estão disponíveis no Anexo A.

A lucratividade da empresa no mesmo período foi de US\$ $315.085,39$ o que representa um percentual de 6,38\% sobre as vendas. Dividindo-se o lucro da empresa pelo número de equipes de venda, a lucratividade média foi de US\$ $17.504,74$ por equipe.

Uma vez estabelecidas as linhas de corte para a análise de desempenho, foi possível posicionar cada uma das equipes de acordo com sua participação no volume de vendas e nos lucros obtidos. De acordo com esse desempenho, as equipes de venda foram posicionadas nos quadrantes da matriz, conforme consta na Figura 1.

\subsection{Posicionamento da indústria têxtil}

A empresa faturou no período analisado US\$469.325,50 com 10 equipes de vendas e obteve um lucro de US\$106.351,47, o que representa um percentual de 22,66\% sobre o preço de venda. Os dados podem ser visualizados no Anexo B. Dividindo-se a receita e o lucro pelo número de equipes de venda tem-se como ponto de corte uma receita média de US\$ 46.932,00 e um lucro médio de US\$ 10.635,00.

Uma vez estabelecidas as linhas de corte para a análise de desempenho foi possível posicionar cada uma das equipes de acordo com a participação no volume de vendas e nos lucros obtidos. De acordo com esse desempenho, as equipes de venda foram posicionadas nos quadrante da matriz. Os resultados estão na Figura 2.

\section{Análise dos resultados}

Com base no posicionamento das equipes de venda nos respectivos quadrantes, o desempenho de cada uma em relação aos resultados obtidos pela empresa pôde ser analisado. Devemos ressaltar que a análise pelo lucro obtido pode estar distorcida por

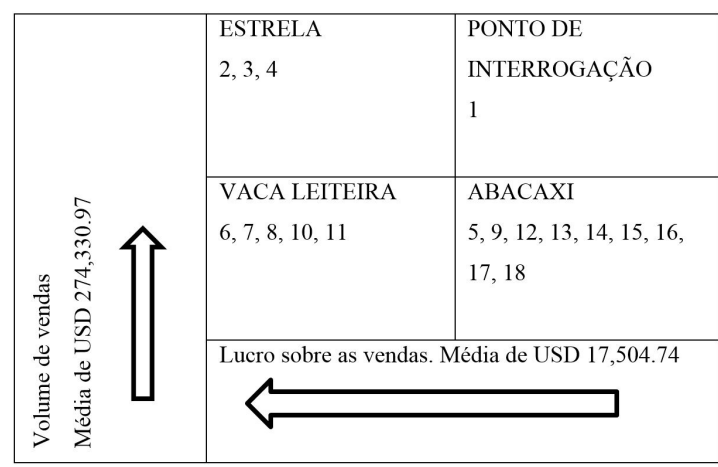

Figura 1. Posicionamento das equipes de venda - indústria de móveis. Fonte: Autores.

\begin{tabular}{|c|c|c|c|}
\hline \multirow{3}{*}{\multicolumn{2}{|c|}{ 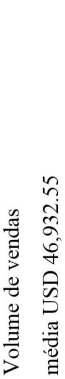 }} & $\begin{array}{l}\text { ESTRELA } \\
\text { A e G }\end{array}$ & $\begin{array}{l}\text { PONTO DE } \\
\text { INTERROGAÇÃO }\end{array}$ \\
\hline & & $\begin{array}{l}\text { VACA LEITEIRA } \\
\text { D e I }\end{array}$ & $\begin{array}{l}\text { ABACAXI } \\
\text { F, B, C, E, H, J }\end{array}$ \\
\hline & & \multicolumn{2}{|c|}{ Lucro sobre as vendas. Média USD $10,635.15$} \\
\hline
\end{tabular}

Figura 2. Posicionamento das equipes de venda - indústria têxtil. Fonte: Autores.

escolhas contábeis como, por exemplo, o critério de rateio adotado. Por essa razão, a análise em relação ao lucro foi mais suscinta, sendo aprofundada na análise da margem de contribuição.

\subsection{Posicionamento das equipes}

Com base nos resultados das empresas foi estabelecido o desempenho médio de cada equipe de vendas, tanto no volume de vendas quanto na lucratividade. A partir dessa média, cada equipe foi posicionada no quadrante que expressa seu desempenho no período analisado.

\subsubsection{Indústria de móveis}

Com base no posicionamento de cada uma das equipes dentro da matriz, conforme a Figura 1, algumas considerações puderam ser feitas sobre o desempenho delas. Em uma análise abrangente pôde-se constatar que há grande concentração no quadrante denominado Abacaxi, no qual estão posicionadas 9 equipes de venda (identificadas pelos números $5,9,12,13,14,15,16,17$ e 18$)$, ou seja, $50 \%$ do total de 18 equipes.

Apesar da teoria do portfólio de produtos afirmar que nesse quadrante os produtos são armadilhas de caixa, deve-se considerar que, neste caso, as equipes de venda são lucrativas. Mesmo que o seu desempenho 
fique abaixo da média da empresa, elas não consomem recursos, apenas dão pouca contribuição. As causas disso deverão ser investigadas no futuro.

Cinco equipes de vendas (identificadas pelos números $6,7,8,10$ e 11) estão posicionadas no quadrante correspondente a Vaca leiteira, ou seja, essas equipes não trazem grandes volumes de vendas para a empresa, porém são as que geram as maiores margens em percentuais sobre as vendas.

Três equipes de vendas (as de números 2, 3 e 4 ) estão posicionadas como Estrela, ou seja, têm uma grande participação no faturamento da empresa e com lucro superior à média da empresa. Uma equipe de vendas está posicionada como sendo Ponto de interrogação, porém, como o que foi medido foi o volume de vendas em relação às margens sobre as vendas, essa equipe gera um grande volume mas seus resultados são negativos. Apesar do grande volume, essa equipe de vendas não contribui para aumentar os lucros da empresa, pelo contrário, consome recursos, diminuindo o lucro total da empresa.

\subsubsection{Indústria têxtil}

Com base nos dados apurados e de acordo com os critérios de classificação pode-se observar na Figura 2 que, das 10 equipes de vendas, $60 \%$ ficaram posicionadas no quadrante Abacaxi. Duas equipes de vendas, identificadas pelas letras D e I, foram classificadas como Vaca leiteira e duas, como Estrela, denominadas pelas letras A e G.

A análise com base nos lucros gerados mostrou que a empresa tem quatro equipes de vendas que produzem lucros superiores às demais e duas equipes de vendas que, além de lucro, têm faturamento superior às outras.

Com base nos dados levantados, a empresa aparentemente tem um problema: a equipe de vendas que gera o maior volume de faturamento e que não contribui positivamente para os resultados. A partir dessa constatação pode-se levantar o questionamento do critério de rateio, que pode alterar os resultados e com isso conduzir a uma decisão equivocada.

De acordo com Horngren et al. (2014), a utilização de um critério aleatório para fazer com que os produtos absorvam os gastos fixos das empresas pode gerar resultados distorcidos e levar a decisões equivocadas. Uma forma de evitá-las é fazer a análise pela margem de contribuição.

\subsection{Margem de contribuição}

De acordo com Horngren et al. (2014), a margem de contribuição é a diferença entre o preço de venda e o custo variável por unidade. Se for utilizada a receita total, a margem de contribuição será a diferença entre as receitas e os custos variáveis totais. Esse resultado é o valor com o qual o produto contribui para o pagamento dos custos fixos da empresa. Os autores consideram que é uma forma mais eficaz de medir a contribuição de cada produto para os resultados da empresa.

$\mathrm{Na}$ análise de custo relacionado ao volume e ao lucro é importante a compreensão do conceito de margem de contribuição. De acordo com os autores, "[...] a margem de contribuição unitária é a diferença entre o preço da venda unitária e o custo variável unitário" (Blocher et al., 2007, p. 180). O seu efeito é aumentar o lucro de acordo com o aumento das unidades vendidas de maneira proporcional, ou seja, um aumento de 10 unidades vendidas aumentará o lucro em 10 vezes a margem de contribuição. No presente trabalho, será o valor com que cada equipe de vendas contribui anualmente para pagar os custos fixos da empresa.

\subsubsection{Indústria de móveis}

Conforme os dados do Anexo A, o valor médio da margem de contribuição de cada equipe de vendas da indústria de móveis foi de US\$37.990,10. Esse resultado foi obtido dividindo-se o total da margem de contribuição no período, que foi de US\$ $683.822,07$, por 18 , que é o número de equipes de vendas da empresa. Dessa forma, aquelas equipes que obtiverem um valor superior a esse serão consideradas de desempenho elevado. A média de faturamento utilizada será a mesma da análise anterior, ou seja, US\$274.330,97. Estabelecidos os critérios, a classificação das equipes de vendas de acordo com a margem de contribuição está ilustrada na Figura 3.

Quando as equipes de vendas são analisadas pela margem de contribuição observa-se que não há nenhuma delas no quadrante Vaca leiteira. A grande maioria das equipes $(5,6,7,8,9,10,11,12,13,14,15$, 16,17 e 18) está posicionada no quadrante Abacaxi, ou seja, tem baixo volume de vendas e margem de contribuição abaixo da média da empresa. Se a análise for feita de acordo com os critérios do portfólio de produtos, a estratégia seria a descontinuidade dessas equipes, porém temos que considerar o conceito de

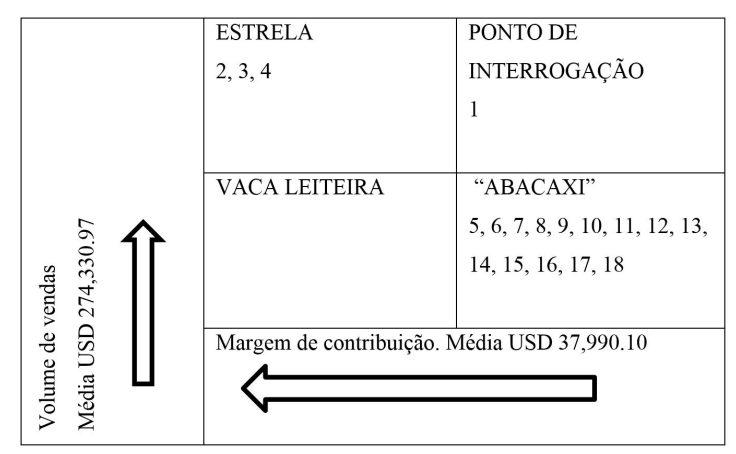

Figura 3. Posicionamento das equipes de venda com base na margem de contribuição - indústria de móveis. Fonte: Autores. 
margem de contribuição e, nesse caso, a decisão mais racional é manter essas equipes, pois mesmo a margem sendo baixa, o fato de ser positiva significa que estão ajudando a empresa a recuperar os seus custos fixos. As estratégias para a atuação nesses mercados é o que deve ser analisado nesse caso, podendo contemplar o aumento do volume comercializado ou o aumento da margem de contribuição.

As equipes Estrela $(2,3,4)$ e Ponto de interrogação (1) não sofreram alteração quando analisadas pelo lucro ou pela margem de contribuição. Isso demonstra que, independentemente do critério, três equipes de vendas contribuem mais para os resultados da empresa e uma equipe de vendas retira valor da empresa, quando analisada pelo lucro líquido, bem como sua contribuição é muito pequena quando analisada pela margem de contribuição.

A comparação do resultado das duas matrizes (lucro e margem de contribuição) mostra a distorção nos resultados que pode ocorrer quando se utiliza um critério de rateio. Algumas unidades de análise que inicialmente constavam como Vaca leiteira, ou seja, com baixos volumes de vendas mas lucro acima da média, quando analisadas pela margem de contribuição mudam de quadrante, passando para Abacaxi, ou seja, apresentam baixo volume e baixa margem de contribuição. Esse fato pode estar sendo agravado pela grande disparidade de volumes existente entre as várias unidades de análise.

A análise do resultado em função do volume pode ajudar a empresa a executar sua estratégia. De acordo com Blocher et al. (2007), a margem de contribuição ajuda a entender como as mudanças no volume de vendas afetam os custos e os lucros.

\subsubsection{Indústria têxtil}

$\mathrm{Na}$ indústria têxtil, conforme os dados do Anexo $\mathrm{B}$, o valor médio da margem de contribuição de cada equipe de vendas foi de US 16.633,42 e o faturamento médio, de US\$46.932,50. Com base no desempenho, as equipes posicionam-se conforme a Figura 4.

A classificação das equipes de vendas de acordo com a margem de contribuição mostra que a grande maioria permanece no quadrante Abacaxi. As equipes A e $\mathrm{G}$ continuam classificadas como Estrela. Enquanto o quadrante Vaca leiteira é alterado: a empresa D passa para Abacaxi e a empresa F, para Vaca leiteira. Das 10 equipes, 6 obtiveram um desempenho abaixo da média tanto em faturamento quanto em margem de contribuição.

\subsection{Análise dos resultados das duas empresas}

As matrizes constantes nas Figuras 1, 2, 3 e 4 mostram que, apesar de as empresas serem de ramos diferentes e apresentarem volume de vendas diferentes, a classificação das equipes de vendas apresenta muitas similaridades. A primeira delas é que a maioria das equipes acaba sendo posicionada como Abacaxi. Na matriz que considera a margem de lucro, as duas empresas ficam com metade das equipes nesse quadrante.

Quando se elabora a matriz com base na margem de contribuição, o volume de equipes no quadrante Abacaxi passa para $60 \%$ na indústria têxtil e de $77 \%$ na indústria moveleira, mostrando que a margem de contribuição é uma medida mais exata para avaliar os resultados.

O quadrante denominado Estrela contém o menor número de equipes de vendas nas duas empresas, o que demonstra que o volume de vendas está concentrado em algumas equipes de vendas e o lucro também. Considerando que a concentração de vendas e de resultados aumenta o risco das empresas, a matriz ilustra onde estão os principais riscos comerciais de cada uma das empresas.

A Tabela 1 mostra que as equipes se posicionam de forma similar quando avaliadas pela margem

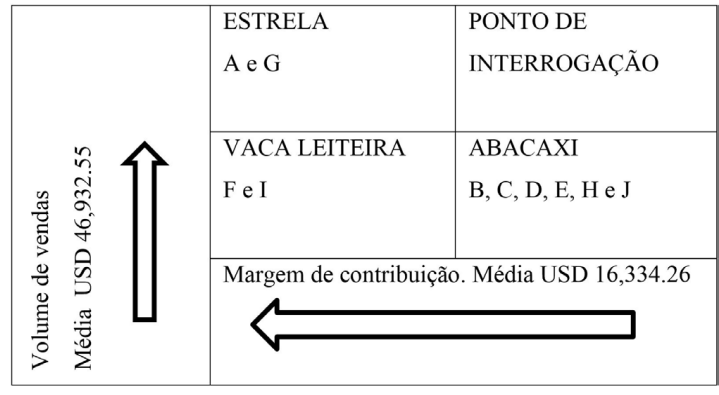

Figura 4. Posicionamento das equipes de venda com base na margem de contribuição - indústria têxtil. Fonte: Autores.

Tabela 1. Classificação das equipes de venda - margem de contribuição $\times$ volume.

\begin{tabular}{cccccc}
\hline \multirow{2}{*}{ QUADRANTE } & \multicolumn{2}{c}{ Indústria moveleira } & & \multicolumn{2}{c}{ Indústria têxtil } \\
\cline { 2 - 3 } \cline { 5 - 6 } & Equipes & $\mathbf{\%}$ & & Equipes & $\%$ \\
\hline Estrela & $2,3,4$ & 16,67 & & A, G & 20 \\
Vaca leiteira & - & 0 & & F, I & 20 \\
Ponto de interrogação & 1 & 5,56 & & - & 0 \\
Abacaxi & $5,6,7,8,9,10,11,12,13$, & 77,78 & & B, C, D, E, H, J & 60 \\
& $14,15,16,17,18$ & & & & 100 \\
\hline
\end{tabular}

Fonte: Autores. 
de contribuição, mesmo que as empresas tenham volumes de venda diferentes, atuem em segmentos diferentes e com equipes diferentes.

\section{Aplicações}

Com a utilização da matriz BCG, as empresas poderão avaliar qualitativamente suas equipes de vendas, mesclando a remuneração relacionada à receita com a remuneração proporcional aos resultados gerados pelas equipes, seja ele o lucro ou a margem de contribuição.

As empresas precisam equilibrar o volume produzido com as margens resultantes das vendas. Dificilmente se consegue alto volume de vendas com margens altas. Com o uso da matriz, a empresa tem uma ilustração de como o volume de vendas e os resultados estão distribuídos e o risco que representam para a consecução dos objetivos da organização.

A matriz de classificação das equipes de venda mostra claramente as características de cada equipe. Com isso fica mais fácil a avaliação do desempenho e o estabelecimento de estratégias de motivação através de remuneração para corrigir as distorções.

Em momentos de alto volume de vendas, a empresa pode tentar aumentar as margens estabelecendo um programa de premiação que contemple a margem de contribuição de cada equipe de vendas. Em momentos de baixo volume de vendas, a empresa pode optar por remunerar mais em razão do volume, nem que para isso seja necessário reduzir um pouco as margens.

Alternativa para o uso da matriz BCG é ensejar o estabelecimento de ações específicas contemplando as características dos mercados, o seu potencial e a posição da empresa em relação a concorrência, subsidiando as equipes de vendas com informações estratégicas indispensáveis à obtenção dos resultados.

\subsection{Cuidados no uso da matriz para produtos e equipes}

Considerando que as equipes de vendas são analisadas qualitativamente em relação ao desempenho de toda a empresa, a tomada de decisão com base na matriz BCG não pode ser feita da mesma forma que a análise de produtos ou unidades de negócio. Nesse tópico são abordadas as principais diferenças na tomada de decisão para produtos e equipes de vendas em cada quadrante da matriz BCG.

Ponto de interrogação: de acordo com Kotler \& Keller (2016), para os produtos é necessário avaliar a continuidade de investimentos nesses negócios. Para as equipes de vendas, principalmente as terceirizadas e remuneradas apenas com percentuais sobre vendas, a avaliação deve se voltar para a capacidade de ampliar as margens de contribuição, pois nas duas empresas estudadas, ainda que as margens de contribuição sejam baixas, são positivas e ajudam a suportar os custos fixos da empresa. Para essas empresas podem ser pensados programas de capacitação ou foco em produtos mais sofisticados, que gerem vendas de maior valor agregado.

Estrela: os produtos desse quadrante nem sempre produzem fluxos de caixa positivos devido à necessidade de investimentos para acompanhar 0 crescimento e os concorrentes. Para as equipes de venda, caracterizam-se como de alta participação no volume de vendas e alta participação nos lucros ou margens de contribuição. Nesse caso, o investimento principal já foi feito, refletindo-se muitas vezes em números de atendimento ou contratação de pessoas que visitam os clientes. Portanto, o maior investimento nas equipes de vendas refere-se à informação e estratégias para manutenção do volume comercializado.

Vaca leiteira: na análise de produtos estão aqueles em que o mercado tem baixo crescimento e o caixa gerado é decorrente de economias de escala. Para as equipes de vendas, nesse quadrante estão aquelas que têm pouca participação nos volumes de venda mas têm alta participação na margem de contribuição. Portanto, deveriam receber investimentos para ampliar o volume de vendas com a manutenção das margens.

Abacaxi: são produtos ou negócios com participação pequena em mercados de baixo crescimento. Geralmente são produtos que podem melhorar seu desempenho em mercados que podem se desenvolver no futuro. Quando se trata de equipe de vendas, são aquelas que têm pequena participação no volume de vendas e pequena participação na margem de contribuição. Essas equipes devem ser analisadas em função da estratégia global da empresa; em alguns casos pode ser possível melhorar seu desempenho através de ações específicas como treinamento e melhorar acompanhamento, entre outros.

Na avaliação do portfólio de produtos, de acordo com Kotler \& Keller (2016), a evolução ideal é que os produtos Ponto de interrogação passem a ser Estrela. Esses, por sua vez, com o tempo transformam-se em Vaca leiteira e, posteriormente, em Abacaxi, quando serão descontinuados. Quando se analisam as equipes de venda, essa evolução não pode ser considerada de forma literal. Em primeiro lugar, porque estamos considerando o desempenho individual das equipes em relação ao desempenho geral da empresa. Dificilmente o volume de vendas ou a sua lucratividade serão as mesmas em todas as áreas. Em segundo lugar, é pouco provável que os volumes de vendas e lucros sejam uniformes e constantes para todas as áreas de atuação e/ou equipes de vendas. Nesse caso, o aconselhável é analisar o desempenho dadas as condições sui generis de cada equipe e sua contribuição para os objetivos da empresa, no sentido de se propor uma nova forma de atuação e remuneração.

\section{Recomendações e aplicações futuras}

No presente trabalho foi usada a média como medida de referência, e essa, talvez, não seja a forma mais adequada de se comparar o desempenho. Ao estabelecer 
a média como parâmetro, a empresa tem um ponto de referência interno, um indicador do desempenho de toda a equipe em relação ao desempenho global da empresa e, com isso, as interferências externas estarão diluídas no índice geral.

Porém deve-se considerar que a média pode estar ocultando disparidades decorrentes de outras variáveis não incluídas no escopo deste estudo. Quando a amostra é pequena, como neste caso, essa distorção poderá ser mais acentuada. Provavelmente, a utilização de desvio padrão junto com a média resulte em medida de análise mais apropriada.

Os dados apurados para este trabalho se referem a um único ano. Aplicando essa abordagem em um tempo mais dilatado, em conjunto ou separadamente, será possível avaliar o desempenho das equipes de vendas de forma mais efetiva, visualizando-se a ocorrência de alteração no desempenho de acordo com o período de tempo analisado, eliminando-se eventuais sazonalidades.

Com base na classificação encontrada neste trabalho, os gestores poderão elaborar estratégias que contemplem os aspectos mais importantes para a organização nas áreas de atuação específicas, tais como aumentar a participação de mercado ou aumentar a lucratividade de uma determinada região. Os dados obtidos neste trabalho poderão servir de base para a empresa decidir sobre a alocação de recursos, na tentativa de buscar melhores resultados em determinadas regiões ou ampliar as regiões de atuação em busca de volume, ou, ainda, reduzir as áreas de atuação em busca de maiores lucros.

$\mathrm{Na}$ avaliação do desempenho das equipes de vendas foram utilizados dois indicadores: os lucros sobre as vendas e a margem de contribuição. Os lucros sobre as vendas foram apurados da forma contábil: sobre os preços de venda foram deduzidos todos os custos e despesas, sendo que os custos e despesas variáveis foram apurados, enquanto os custos e despesas fixos foram rateados e deduzidos do preço de venda. Como o rateio pode distorcer os resultados mostrando lucros que não são reais, foi feita a análise de acordo com a margem de contribuição.

A avaliação através da margem de contribuição é considerada a mais recomendável para a análise gerencial, uma vez que é apurada deduzindo-se do preço de venda todos os custos e despesas variáveis. Dessa forma somente os gastos identificados com o produto são considerados e, com isso, são evitadas as distorções do rateio. As duas matrizes mostram essas diferenças e, por isso, é sugerida a utilização da margem de contribuição nas avaliações gerenciais.

As análises elaboradas neste trabalho poderão ser utilizadas para avaliar o desempenho da empresa em relação aos concorrentes, se existirem dados disponíveis. Uma aplicação prática é verificar qual a lucratividade dos concorrentes, bem como quais das equipes da empresa contribuíram para manter essa lucratividade nos mesmos patamares relativos e quais as que afetaram o desempenho. Com os dados do trabalho é possível simular algumas decisões como, por exemplo, verificar o desempenho da empresa se fossem descontinuadas as áreas com desempenho fraco.

Outra aplicação deste trabalho poderá ser em campanhas de vendas para melhorar o desempenho das equipes, o que poderá ser feito em relação às demais ou com base no potencial de mercado. Nas campanhas poderão ser propostos critérios de avaliação que permitam melhorar o mix de produtos, contemplando-se os de maior margem de contribuição.

Uma das dificuldades dos gestores é fazer com que os interesses das pessoas estejam alinhados com os interesses da organização. Uma das formas de fazer com que isso aconteça é ter um sistema de controle e avaliação que permita sua ligação com um sistema de remuneração, de maneira que promova a mudança desejada no comportamento. Por meio de matriz BCG que contemple o volume de vendas e os resultados financeiros, a avaliação da área comercial poderá ser mais eficiente, uma vez que, além do volume, haverá possibilidade de visualizar, também, a margem de contribuição e o lucro. Em outras palavras, avaliar a qualidade da venda. Então, os objetivos da empresa poderão ser estabelecidos de forma mais efetiva do que simples metas quantitativas de vendas.

Pesquisa realizada por Johnson et al. (2001) revela que em organizações nas quais as pessoas são recompensadas por sistemas de controle e avaliação seu comportamento é modificado por esse entendimento, bem como aumenta o espírito de colaboração. A utilização de ferramenta que avalie os objetivos, tanto de forma quantitativa quanto qualitativa, poderá auxiliar as empresas a estabelecerem objetivos mais facilmente visualizados e assim permitir uma troca de experiências entre as equipes de venda, no sentido de tentar expandir práticas bem-sucedidas.

\section{Considerações finais}

Ao estabelecer controles gerenciais a empresa busca utilizar ferramentas que avaliem e direcionem as ações para os objetivos que ela espera atingir, bem como ter informações que a auxiliem a avaliar o desempenho das pessoas e evitar comportamentos inadequados.

Este trabalho avaliou o desempenho das equipes de vendas de forma qualitativa e quantitativa. $\mathrm{O}$ aspecto quantitativo está presente no volume de vendas de cada equipe, enquanto o aspecto qualitativo é o resultado de cada equipe. Neste trabalho, as equipes são avaliadas de acordo com a margem de contribuição e o lucro, bem como pela participação de cada equipe nos resultados da empresa. Para tal foi utilizada a metodologia da matriz BCG. Na sua versão original, essa matriz coloca no eixo horizontal a participação relativa da empresa no mercado e no eixo vertical a taxa de crescimento do mercado. 
Foram feitas duas adaptações da matriz para avaliar o desempenho das equipes de vendas. Na primeira, o eixo horizontal representa o lucro gerado pelas equipes de vendas individualmente e o eixo vertical, o volume de vendas expresso em unidades monetárias. $\mathrm{Na}$ segunda adaptação, o eixo horizontal representa a margem de contribuição de cada equipe de vendas e o eixo vertical, o volume de vendas em unidades monetárias.

A aplicação dessa metodologia foi feita em uma indústria de móveis de médio porte e uma indústria têxtil. Após a apuração dos custos de cada produto foi apurado o lucro de cada unidade vendida e, em seguida, o lucro anual de cada equipe de vendas. Para tal, o lucro unitário foi multiplicado pelo volume vendido de cada um dos produtos comercializados. A classificação, de acordo com o desempenho, foi colocada em um dos quatro quadrantes da matriz, conforme o volume de vendas e os lucros sobre as vendas.

Quando analisadas de acordo com o lucro, a matriz gerada posicionou a metade das equipes de venda no quadrante Abacaxi, apenas uma como Ponto de interrogação, três como Estrela e cinco como Vaca leiteira.

Para evitar distorções geradas pelo rateio dos custos fixos, foi calculada a margem de contribuição de cada produto e a margem de contribuição total de cada equipe de vendas. Quando analisadas de acordo com a margem de contribuição, a grande maioria das equipes ficou posicionada no quadrante Abacaxi, uma ficou no quadrante Ponto de interrogação e três equipes ficaram posicionadas como Estrela.

Quando comparados os diferentes resultados gerados nas duas matrizes, fica visível que o rateio dos custos fixos pode alterar os resultados e gerar distorções nas análises gerenciais.

Os resultados da avaliação das equipes de venda mostram um comportamento semelhante das equipes de venda das duas empresas, em que um pequeno número de equipes representa a maior parcela de vendas e de resultados das empresas.

O trabalho avaliou o desempenho relativo de cada equipe da área comercial. Para tal, foram consideradas como ponto de referência as médias de faturamento, lucro e margem de contribuição da empresa. Então, cada equipe de vendas foi posicionada dentro da matriz de acordo com seu desempenho em relação à média da empresa.

A matriz BCG adaptada para avaliar o desempenho de uma equipe de vendas se mostrou útil devido à avaliação qualitativa do volume de vendas, porém é sugerido que a análise não seja feita da mesma forma como estabelecido originalmente. Em primeiro lugar, produtos posicionados como Abacaxi segundo a análise de portfólio devem ser descontinuados. Porém, quando se trata de regiões de atuação ou de equipes de venda, como é o caso deste estudo, isso não pode ser decidido sem uma análise mais detalhada que considere outros aspectos, tais como o reflexo nas demais áreas quando se elimina uma área com margem de contribuição positiva, mesmo que relativamente pequena. $\mathrm{O}$ mesmo se aplica em relação ao lucro.

O trabalho mostrou como a utilização da matriz BCG pode ser adaptada para a avaliação qualitativa das equipes de vendas e das regiões de atuação. Poderá ser usada, também, para estabelecer estratégias de atuação no mercado. Outra utilidade deste estudo é prover novos subsídios para o estabelecimento de promoções internas de vendas, premiando não somente os maiores volumes de vendas mas também as vendas mais lucrativas.

\section{Agradecimentos}

Os autores agradecem os pareceres dos avaliadores anônimos que ajudaram a melhorar o resultado deste trabalho.

\section{Referências}

Allio, R. J., \& Randall, R. M. (2010). Kiechel's history of corporate strategy. Strategy and Leadership, 38(3), 29-34. http://dx.doi.org/10.1108/10878571011042087.

Blocher, E. L., Chen, K. H., Cokins, G., \& Lin, T. W. (2007). Gestão estratégica de custos. São Paulo: McGraw-Hill.

Comitê de Pronunciamentos Contábeis - CPC. (2010). CPC 02 (R2): efeitos das mudanças nas taxas de câmbio e conversão de demonstrações contábeis. Brasília: CPC. Recuperado em 12 de Abril de 2016, de http://www.cpc. org.br/CPC/Documentos-Emitidos/Pronunciamentos/ Pronunciamento? $\mathrm{Id}=9$

Calandro, J., Jr., \& Lane, S. (2007). A new competitive analysis tool: the relative profitability and growth matrix. Strategy and Leadership, 35(2), 30-38. http:// dx.doi.org/10.1108/10878570710734516.

Connel, R. B. (2010). The attractiveness-competitiveness matrix: a methodology used to assist policy makers select priorities for industrial development initiatives. International Journal of Business and Management, 5(7), 3-13.

Damodaran, A. (2007). Corporate finance: theory and practice (2nd. ed.). India: Wiley.

Flamholtz, E. (1996). Effective organizational control: a framework, applications, and implications. European Management Journal, 14(6), 596-611. http://dx.doi. org/10.1016/S0263-2373(96)00056-4.

Horngren, C. T., Sundem, G. L., Burgstahler, D., \& Schatzberg, J. (2014). Introduction to management accounting (16th ed.). New York: Pearson.

Johnson, P., Cassell, C., Close, P., \& Duberley, J. (2001). Performance evaluation and control: supporting organizational change. Management Decision, 39(10), 841-851. http://dx.doi.org/10.1108/00251740110402337. 
Kotler, P., \& Keller, K. L. (2016). Marketing management (15th ed.). New York: Pearson.

Ladley, D., Wilkinson, I., \& Young, L. (2015). The impact of individual versus group rewards on work group performance and cooperation: a computational social science approach. Journal of Business Research, 68(11), 2412-2425. http://dx.doi.org/10.1016/j.jbusres.2015.02.020.

Lopes, E. L., Moretti, S. L. A., \& Alejandro, T. B. (2011). Avaliação de justiça e intenção de turnover em equipes de vendas: teste de um modelo teórico. Revista de Adminstração de Empresas, 51(6), 553-567. http:// dx.doi.org/10.1590/S0034-75902011000600005.

Merchant, K. A. (1998). Modern management control systems: text \& cases. Upper Saddle River: Prentice-Hall.

Otley, D. (1999). Performance management: a framework for management control systems research. Management Accounting Research, 10(4), 363-382. http://dx.doi. org/10.1006/mare.1999.0115.
Ouchi, W. G. (1979). A conceptual framework for the design of organizational control mechanisms. Management Science, 25(9), 833-848. http://dx.doi.org/10.1287/ mnsc.25.9.833.

Owoyemi, O. O., \& Ekwoaba, J. O. (2014). Organisational culture: a tool for management to control, motivate and enhance employees' performance. American Journal of Business and Management, 3(3), 168-177. http:// dx.doi.org/10.11634/216796061403514.

Rajagopal, \& Rajagopal, A. (2008). Team performance and control process in sales organizations. Team Performance Management, 14(1-2), 70-85. http://dx.doi. org/10.1108/13527590810860212.

Wilkes, M. S., Srinivasan, M., \& Flamholtz, E. (2005). Effective organizational control: implications for academic medicine. Academic Medicine, 80(11), 1054-1063. http://dx.doi.org/10.1097/00001888-200511000-00014. PMid:16249305. 
Anexo A. Desempenho das equipes de venda em US\$ - fábrica de móveis.

\begin{tabular}{|c|c|c|c|c|c|c|c|c|}
\hline $\begin{array}{l}\text { Equipes } \\
\text { de } \\
\text { venda }\end{array}$ & Valor & Participação & $\begin{array}{c}\text { Margem } \\
\text { de } \\
\text { contribuição } \\
\text { em valor }\end{array}$ & $\%$ & Custos fixos & Lucro & $\begin{array}{c}\text { Lucro } \\
\%\end{array}$ & Participação \\
\hline 1 & $1.567 .036,68$ & $31,73 \%$ & $37.660,69$ & $2,40 \%$ & $141.458,92$ & $-103.798,23$ & $-6,62 \%$ & $-32,94 \%$ \\
\hline 2 & $1.014 .606,30$ & $20,55 \%$ & $199.929,98$ & $19,71 \%$ & $65.880,64$ & $134.049,34$ & $13,21 \%$ & $42,54 \%$ \\
\hline 3 & $533.243,14$ & $10,80 \%$ & $94.780,40$ & $17,77 \%$ & $35.229,83$ & $59.550,57$ & $11,17 \%$ & $18,90 \%$ \\
\hline 4 & $506.507,93$ & $10,26 \%$ & $71.512,66$ & $14,12 \%$ & $36.679,80$ & $34.832,87$ & $6,88 \%$ & $11,06 \%$ \\
\hline 5 & $211.095,61$ & $4,27 \%$ & $31.508,71$ & $14,93 \%$ & $7.161,44$ & $24.347,27$ & $11,53 \%$ & $7,73 \%$ \\
\hline 6 & $175.324,48$ & $3,55 \%$ & $35.941,57$ & $20,50 \%$ & $11.708,53$ & $24.233,05$ & $13,82 \%$ & $7,69 \%$ \\
\hline 7 & $132.745,49$ & $2,69 \%$ & $27.601,11$ & $20,79 \%$ & $7.747,04$ & $19.854,07$ & $14,96 \%$ & $6,30 \%$ \\
\hline 8 & $125.957,19$ & $2,55 \%$ & $30.941,77$ & $24,57 \%$ & $6.811,09$ & $24.130,67$ & $19,16 \%$ & $7,66 \%$ \\
\hline 9 & $125.019,00$ & $2,53 \%$ & $16.815,04$ & $13,45 \%$ & $8.814,62$ & $8.000,42$ & $6,40 \%$ & $2,54 \%$ \\
\hline 10 & $113.892,56$ & $2,31 \%$ & $32.467,42$ & $28,51 \%$ & $8.976,49$ & $23.490,93$ & $20,63 \%$ & $7,46 \%$ \\
\hline 11 & $106.879,35$ & $2,16 \%$ & $29.769,90$ & $27,85 \%$ & $4.899,47$ & $24.870,43$ & $23,27 \%$ & $7,89 \%$ \\
\hline 12 & $76.618,36$ & $1,55 \%$ & $21.211,55$ & $27,68 \%$ & $16.160,49$ & $5.051,06$ & $6,59 \%$ & $1,60 \%$ \\
\hline 13 & $51.590,44$ & $1,04 \%$ & $10.473,30$ & $20,30 \%$ & $8.681,70$ & $1.791,60$ & $3,47 \%$ & $0,57 \%$ \\
\hline 14 & $28.544,76$ & $0,58 \%$ & $6.575,34$ & $23,04 \%$ & $3.793,48$ & $2.781,87$ & $9,75 \%$ & $0,88 \%$ \\
\hline 15 & $126.452,41$ & $2,56 \%$ & $26.359,98$ & $20,85 \%$ & $1.997,60$ & $24.362,37$ & $19,27 \%$ & $7,73 \%$ \\
\hline 16 & $26.258,33$ & $0,53 \%$ & $6.163,45$ & $23,47 \%$ & $1.652,28$ & $4.511,17$ & $17,18 \%$ & $1,43 \%$ \\
\hline 17 & $11.934,37$ & $0,24 \%$ & $2.982,85$ & $24,99 \%$ & 804,84 & $2.178,01$ & $18,25 \%$ & $0,69 \%$ \\
\hline \multirow[t]{2}{*}{18} & $4.251,20$ & $0,09 \%$ & $1.126,35$ & $26,49 \%$ & 278,41 & 847,94 & $19,95 \%$ & $0,27 \%$ \\
\hline & $4.937 .957,60$ & & $683.822,07$ & & $368.736,67$ & $315.085,40$ & $6,38 \%$ & \\
\hline
\end{tabular}


Anexo B. Desempenho das equipes de venda em US\$ - fábrica de produtos têxteis.

\begin{tabular}{crrrrrrrr}
\hline $\begin{array}{c}\text { Equipes } \\
\text { de venda }\end{array}$ & Valor & Participação & $\begin{array}{c}\text { Margem } \\
\text { de } \\
\text { contribuição } \\
\text { em valor }\end{array}$ & \% & Custos fixos & Lucro & $\begin{array}{c}\text { Lucro } \\
\text { \% }\end{array}$ & Participação \\
\hline A & $181.316,15$ & $38,63 \%$ & $65.038,10$ & $35,87 \%$ & $21.790,41$ & $43.247,69$ & $23,85 \%$ & $40,66 \%$ \\
B & $21.697,75$ & $4,62 \%$ & $8.316,75$ & $38,33 \%$ & $2.580,22$ & $5.736,52$ & $26,44 \%$ & $5,39 \%$ \\
C & 929,10 & $0,20 \%$ & 328,53 & $35,36 \%$ & 118,07 & 210,46 & $22,65 \%$ & $0,20 \%$ \\
D & $41.113,54$ & $8,76 \%$ & $15.635,48$ & $38,03 \%$ & $4.942,83$ & $10.692,65$ & $26,01 \%$ & $10,05 \%$ \\
E & $35.871,99$ & $7,64 \%$ & $5.958,34$ & $16,61 \%$ & $6.786,52$ & $(828,18)$ & $-2,31 \%$ & $-0,78 \%$ \\
F & $46.352,33$ & $9,88 \%$ & $14.670,51$ & $31,65 \%$ & $6.377,14$ & $8.293,37$ & $17,89 \%$ & $7,80 \%$ \\
G & $86.992,70$ & $18,54 \%$ & $32.831,05$ & $37,74 \%$ & $10.286,90$ & $22.544,15$ & $25,91 \%$ & $21,20 \%$ \\
H & $7.025,70$ & $1,50 \%$ & $2.911,45$ & $41,44 \%$ & 896,91 & $2.014,54$ & $28,67 \%$ & $1,89 \%$ \\
I & $42.674,06$ & $9,09 \%$ & $18.430,93$ & $43,19 \%$ & $5.519,11$ & $12.911,81$ & $30,26 \%$ & $12,14 \%$ \\
J & $5.352,18$ & $1,14 \%$ & $2.213,13$ & $41,35 \%$ & 684,67 & $1.528,45$ & $28,56 \%$ & $1,44 \%$ \\
& $469.325,50$ & & $166.334,26$ & $35,44 \%$ & $59.982,78$ & $106.351,47$ & $22,66 \%$ & $100,00 \%$ \\
\hline
\end{tabular}

